\title{
Tipologías psicodélicas en la iconografía del Rock
}

\author{
Eduardo Rodríguez Clavo \\ Universidad Complutense de Madrid. Facultad de Geografía e Historia \\ Departamento de Historia del Arte III (Contemporáneo) \\ ediclavo@wanadoo.es
}

\begin{abstract}
RESUMEN
Un recorrido icónico a través de los elementos gráficos recurrentes que han sido capaces de configurar una iconografía del Rock en el periodo psicodélico, aproximadamente desde 1966 hasta finales de la década. Selección, catálogo y análisis de portadas de discos en el formato LP y de pósters anunciadores de conciertos y otros eventos. Fuentes plásticas y tipográficas: orígenes, apropiaciones y parodias. Intertextualidad de los medios de comunicación de masas y su difusión globalizadora. La permeabilidad de los artistas clave y su trasvase de influencias: The Beatles-Bob Dylan. La comunicación audiovisual potenciada por el consumo de sustancias psicoactivas, principalmente LSD, y finalmente la sinestesia como capacidad sensorial amplificada por las citadas drogas para lograr un deleite estético novedoso y alucinante.
\end{abstract}

Palabras clave: Iconografía; música Rock; Pósters; Portadas de discos; formato LP; Simbología; Sinestesia.

\section{Psychedelic tipologies through Rock iconography}

\begin{abstract}
An iconic journey through recurrent graphic elements capables to shape a Rock iconography during psychedelic period, between 1966 until the end of the sixties.

Selection, catalogue and analysis of record covers in LP format and concert and other events posters. Plastic and typographical sources: origins, adaptations and parodies. Mass media textuality and global spreading. Permeability of key artists and influence shift: The Beatles-Bob Dylan. Audiovisual communication empowered by psychoactive substances, mostly LSD, and finally synestesia as sensorial capacity amplified by the aforementioned drugs to achieve a new and mind blogging aesthetic joy.
\end{abstract}

Key words: Iconography; Rock music; Posters; Record covers; LP format; System of symbols; Synestesia. 
A partir de la experiencia psicodélica, tras la ingesta de una sustancia psicoactiva como la LSD (dietilamida del ácido lisérgico) ${ }^{1}$, se producen una serie de cambios sensoriales que afectan la percepción del ser humano: distorsiones lumínicas y cromáticas como las más representativas. La pintura ha tratado de plasmar esas visiones de un modo aproximativo, incompleto, ya que necesitaría una ayuda suplementaria: la participación sinestésica del espectador. Es ahí, en la confusión de los sentidos, en la sinestesia, donde radicaría el embrión de lo psicodélico, su novedad; en el juego del participante en el rito, en la "experiencia" adquirida después del viaje proporcionado por la acción estupefaciente del ácido.

El arte psicodélico, en su manifestación plástica -estática y bidimensional-, aparece como mero reflejo pasivo de la "experiencia psicodélica", aquella que es capaz de habilitarlo, de insuflarle aliento vital, dinamismo, por eso, en su estado latente aquél se muestra prácticamente inerte, laso. Sólo inmerso en el éxtasis químico el observador podría llegar a degustar esas sensaciones extraterrestres: los espectros multicolores en el juego de curva-contracurva, la globularidad tempestuosa de las formas o la liquidez de los sólidos y, completado con la música, llegar a paladear los registros sobreagudos, el efecto ululante de los artificios electrónicos y en definitiva el delirio sinestésico de la confusión de los sentidos: el clímax psicodélico.

Se podría afirmar que el arte psicodélico y sus principales manifestaciones plásticas del periodo 1965-1970 (portadas de discos y carteles anunciadores de conciertos) configuraron un fenómeno de raíz popular con un carácter eminentemente utilitario. Se debe observar que su éxito radicó en una hábil y oportuna exposición pública alentada gracias a los medios de comunicación de masas y dirigida sobre sectores de aquella sociedad de consumo por unas minorías juveniles dotadas de talento y desparpajo.

La utopía social, la liberación sexual, el consumo de drogas y el ímpetu del rock conformaron un caldo de cultivo idóneo para que esta opción denominada "contracultura" postulara sus atrevidos cánones, estableciendo nuevos usos y costumbres, desmontando rancios tics de la sociedad burguesa de posguerra y apostando por un estilo visual extravagante y audaz.

Dentro de ese periodo vibrante que fueron los años sesenta del siglo XX, la música popular, y más concretamente el rock $^{2}$, ocupa un lugar predominante como catalizador, motor y fuente de otras tantas derivaciones del arte: popular, masivo y facturado para el consumo pero con valores iconográficos reseñables y dignos de estudio, comprensión y catálogo. A mediados de la década y ya con los principios básicos del movimiento contracultural filtrándose entre creadores diversos, se podría hablar de la ilustración gráfica: carteles, portadas de discos, libros, revistas, cómics y grafía en general, como la base sobre la que se asentarían los caracteres recurrentes de esta nueva

1 Se puede consultar como texto de iniciación: HOFFMANN, Albert, La historia del LSD, Barcelona, Ed. Gredos, 2006. También, con un enfoque más sociológico: MARTIN A. Lee \& SHLAIN, Bruce, Acid dreams: the complete social history of LSD: The C.I.A., the sixties and beyond, New York, Grove Press, 1985.

2 Entendiendo como tal la acepción genérica de éste como un estilo propio, no un subgénero. Así, como convención, se puede establecer Rock como género matriz que acogería otros subgéneros deudores (Rock \& Roll, Beat, Garaje, Psicodelia, Hard Rock, Heavy Rock, Rock Sinfónico, Glam Rock, Punk, New Wave, etc., etc.,) 
imaginería, de ámbito y difusión popular, definida como psicodélica. Dos serían los elementos fundamentales sobre los que se construyen esas constantes iconográficas: color (vivo, chirriante, fluorescente) y formas (abigarradas, orgánicas, vibrantes). En cuanto a los soportes físicos tendríamos que referirnos a los carteles o pósters (anunciadores de conciertos de rock y otros eventos relacionados) y a las portadas de los discos de vinilo de larga duración (formato conocido como LP). En ambos casos la música rock actúa como carburante de ese impulso creativo que conforma la expresión psicodélica. Esa inmersión, inducida por la ingestión de drogas psicoactivas (LSD, peyote o mescalina) se ve potenciada con la impresión de esas imágenes sobre el cartón satinado del envoltorio de los discos que, a su vez, contienen la música grabada que posibilita la sinestesia alucinante.

En estas representaciones gráficas se combinan composiciones biomórficas plenas de saturación cromática acompañadas de tipografías distorsionadas con el propósito de crear un efecto llamada para iniciados. No obstante aparecen con cierta claridad una serie de precedentes que confluyen en las obras, se amalgaman en el nuevo lenguaje visual y pueden ser considerados fuentes, a saber: la simplificación gráfica del Pop art y su predilección por tintas planas, carentes de modulación. La excitación ocular del $O p$ art, el detallismo botánico Pre-rafaelita, el grafismo libre y manual de los carteles de Toulouse-Lautrec, los diseños orgánicos y florales del también cartelista Alphonse Mucha, la linealidad neta de Aubrey Beardsley, la obra visionaria de William Blake, los paisajes oníricos -ingenuos y terroríficos- de El Bosco, las ilustraciones fantásticas de Edmund Du Lac y Arthur Rackham, la imbricada caligrafía céltica, los simbolistas franceses Odilon Redon y Gustave Moreau y hasta el impresionismo científico de Paul Signac, la plástica metafísica de De Chirico y el surrealismo de Salvador Dalí y Joan Miró. Aunque si hubiera que elegir un elemento distintivo sobre el que poder sintetizar la experiencia psicodélica traducida a un lenguaje plástico ese sería, sin duda, el color. El delirio cromático es la característica esencial de las representaciones psicodélicas, desde las vibraciones de un póster o la portada de un LP, hasta la exuberancia de una composición musical o el torrente lumínico de un Light Show.

En lo referido a la música pop, inmediatamente después del periodo efervescente de los primeros años sesenta y tras el huracán mediático propiciado por la Beatlemania se produce una suerte de evolución que se percibe gracias a la inclusión de elementos tomados de otros géneros musicales: Jazz, Folk, Clásica, Electrónica o Music Hall. También las innovaciones técnicas permiten un mayor grado de experimentación en los estudios de grabación llegando a convertirse en genuinos laboratorios de sonido. Es necesario también referirse a la evolución de los textos de las canciones, hasta ese momento relacionados casi exclusivamente con inquietudes juveniles elementales (amor, sexo incipiente) o con subculturas diversas (automóviles, motocicletas, surf). La irrupción de un músico como Bob Dylan llevará pareja esa transformación; desde sus comienzos en 1962 cuando sus mensajes sociales se acompañaban de una escueta guitarra acústica y armónica, dentro de la ortodoxia Folk, hasta la explosión de su Rock Acido, en 1965, con guitarras eléctricas, bajo y batería y con la proliferación de textos trufados de imaginería compleja y barniz surrealista. 
Otro de los ingredientes lo constituye el propio formato LP. A partir de 1966 es en las carátulas de los discos de larga duración donde el binomio música/imagen se hace más elocuente. Se pasa de una colección de canciones o recopilación de éxitos con el artista fotografiado en la portada y acompañado de una breve información telegráfica a trabajos conceptuales con alambicadas presentaciones, inclusión de textos y arriesgados formatos en los que los temas -ya no canciones- se funden, se alargan y hasta se encadenan en suites sin solución de continuidad.

No se debe ignorar tampoco la influencia decisiva de las drogas y su expansión creciente durante el segundo lustro de la década de los años sesenta. En una primera instancia los derivados del cannabis (marihuana y hachís) ya utilizados en los círculos Hipster y Beatnik de los años cuarenta y cincuenta en Estados Unidos (asociados al Jazz como música de referencia) y a continuación la dietilamida del ácido lisérgico, LSD, potente alucinógeno que eclosiona en la mutación del rock a partir de 1965 y posibilita la confusión sensorial, la sinestesia mediante la que música e imágenes, tonos sonoros y cromáticos se entreveran y amplifican mutuamente. Se podría afirmar que en la experiencia psicodélica confluyen una serie de factores extraídos de la capacidad sinestésica del rock y las imágenes multicolores de las portadas de los discos que propician la creación de un microcosmos iconográfico donde unos medios se diluyen en otros, donde el todo -lo psicodélico- se alimenta de los diversos artefactos audiovisuales que lo nutren. Así, el placer sensorial de la audición musical se podría elevar a la categoría de "experiencia psicodélica" en la interacción del rock (percibido a través de potentes equipos estereofónicos) unido a las imágenes sugerentes (creaciones gráficas en las carátulas de los LP) y todo ello auspiciado por las alucinaciones estupefacientes del ácido lisérgico.

\section{PÓSTERS PSICODÉLICOS}

Por lo que respecta a los pósters anunciadores de conciertos, sus creadores más sobresalientes surgieron en dos ciudades psicodélicas por excelencia asociadas al desarrollo y evolución del rock en los años sesenta: San Francisco y Londres.

Rick Griffin, Victor Moscoso, Alton Kelley, Wes Wilson y Stanley "Mouse" Miller fueron residentes de Haight Ashbury, el barrio bohemio y Hippie de San Francisco. Aunque los diseñadores, ilustradores y artistas asentados allí trabajaron para variedad de clientes durante el periodo psicodélico, entre 1965 y 1970, el grueso de su producción más relevante fue realizada para anunciar conciertos de rock y otras actividades relacionadas que tuvieron lugar en las tres salas más representativas de la ciudad californiana: Avalon Ballroom, Fillmore Auditórium y Matrix Club.

Stanley "Mouse" Miller (1940), fue uno de los ilustradores pioneros a la hora de dar a conocer los nuevos grupos del Rock Acido de California ${ }^{3}$. Nacido en Detroit (Michigan), había aprendido los rudimentos de la ilustración junto a su padre, animador de viñetas para Walt Disney, y se estableció en San Francisco en 1965, fundando

3 Para una información estrictamente musical sobre el mismo se puede consultar: ORDOVÁS, Jesús, El Rock Acido de California, Madrid, Ed. Júcar, 1975. 


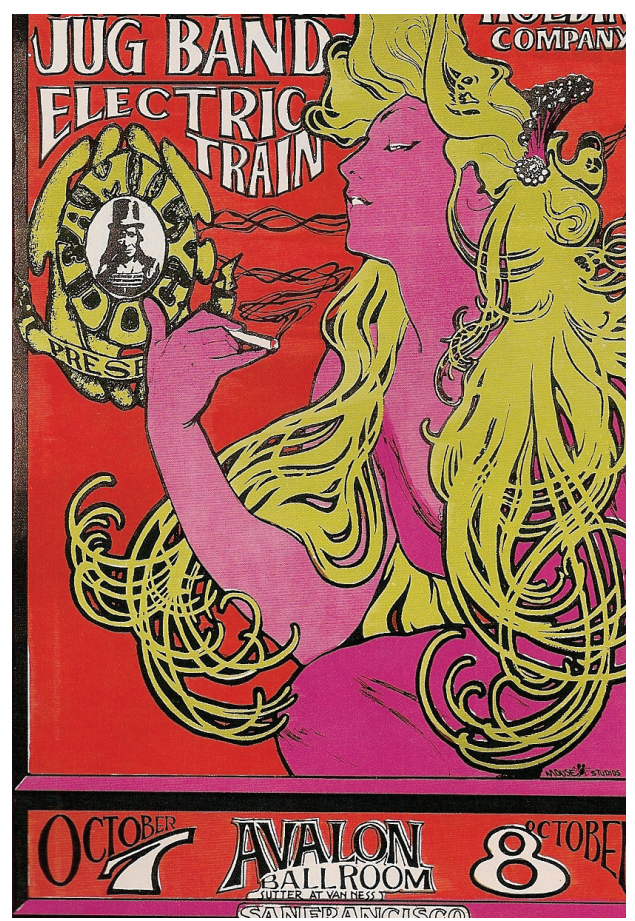

Fig.1. Mouse \& Kelley Studio; Girl with green hair (1966).

junto a su socio y también dibujante Alton Kelley, Mouse \& Kelley Studios. Bajo esta denominación crearon carteles anunciadores de conciertos y carátulas de discos hasta bien entrada la década de los años ochenta ${ }^{4}$. No obstante en el periodo más álgido de la psicodelia (entre 1966 y 1967), la producción de Mouse \& Kelley era, como mínimo, de un póster semanal anunciador de los conciertos del Avalon Ballroom. En el análisis formal de muchas de estas obras los caracteres tipográficos protagonizan la parte esencial del mensaje. El nombre del grupo, la fecha, hora y lugar del concierto pasan a cobrar identidad propia. Los tipos de letra, en una gran mayoría inspirados directamente por la grafía Art Nouveau de autores como Alphonse Mucha, Pierre Bonnard o Jules Chéret ${ }^{5}$, ahora se retuercen, se dinamizan y son constreñidos en el espacio cuadrangular estandarizado de $14 \times 20$ pulgadas $(100 \times 150 \mathrm{~cm} \text {. })^{6}$. Los colores son puros, carentes de modulación y se potencia su vibración ocular al situar complementarios contiguos. Se sacrifica la inteligibilidad en aras del efectismo psicodélico. Las composiciones suelen ser abigarradas, con poco "aire" entre los motivos y con

\footnotetext{
4 Se pueden consultar más detalles en su autobiografía: MOUSE, Stanley, Freehand; the art of Stanley Mouse, Berkeley, SLG Books, 1973.

5 Vid. BARNICOAT, John, Los carteles; su historia y su lenguaje, Barcelona, Ed. Gustavo Gili, 2003.

6 SCULATTI, Gene \& SEAY, Davin, San Francisco nights; The psychedelic music trips, 1965-1968, London, Sidgwick \& Jackson, 1985, p. 103.
} 
una disposición jerárquica en la que el nombre del grupo cabeza de cartel destaca sobre el resto. En los trabajos iniciales de Mouse \& Kelly las influencias Art Nouveau son recurrentes en la decoración floral y en el empleo de sugerentes figuras femeninas. Girl with green hair (1966) (fig. 1) es un claro trasunto de las obras de Alphonse Mucha, Papier Job (1897) o Salon des Cent (1896). No obstante se podrían definir los pósters del tándem Mouse \& Kelley como representativos de una línea clara donde la tipografía y las decoraciones orgánicas se entreveran con componentes más propiamente psicodélicos como la ilegibilidad tipográfica, los colores complementarios saturados y el collage de elementos anticuarios (figuras femeninas, efectos navales, indios nativos norteamericanos, animales, etc.). Lo fundamental para ellos era el "poder de atracción" de las imágenes reconocibles".

Victor Moscoso (1936) aporta un sentido mucho más lisérgico, entendiendo como tal la yuxtaposición de elementos gráficos a base de textos muy distorsionados y tipografías globulares en composiciones más netas, cercanas al Pop art. El propio Moscoso define su estilo como "ecléctico contemporáneo" y cita como fuentes de inspiración elementos gráficos y artefactos de la cultura popular y de masas (postales, comics, revistas y periódicos) ${ }^{8}$. De origen español -nacido en La Coruña- y con formación académica en la Universidad de Yale, donde fue discípulo de Josef Albers, Moscoso abunda en las constantes ya enumeradas pero con la particularidad de llevar hasta el extremo el grado de excitación óptica a través del empleo del color y la yuxtaposición de tramas de líneas paralelas. Se puede apreciar en sus obras una aplicación práctica de las teorías cromáticas de su maestro Josef Albers 9 .

Desde 1966, en sus pósters para el Avalon Ballroom y el Matrix Club, Moscoso muestra combinaciones de colores primarios intensos y saturados, como cargados de electricidad, que procuran una vibración similar a las realizaciones coetáneas $O p$ art de Víctor Vasarely o Bridget Riley. Sobre esta última el crítico David Mellor afirmaba que sus obras estaban dotadas de una corriente eléctrica y ella misma, refiriéndose a sus líneas y tramas, hablaba también de "alto voltaje" ${ }^{10}$. En una obra como Neon Rose \# 12, Chambers Brothers (1967) (fig. 2) se aprecia esa concreción compositiva así como el parpadeo inducido por la yuxtaposición de dos colores (naranja y azul). En otros trabajos queda de manifiesto esa electricidad óptica que recorre la superficie del póster: Flower Pot. Blue Cher (1967).

Robert Wesley Wilson (Wes Wilson) (1941) es otro de los denominados "Cinco Grandes" creadores de pósters psicodélicos de San Francisco, junto a "Mouse”, Kelley, Moscoso y Griffin. Wilson trabajó principalmente para publicitar los conciertos del Fillmore West Auditórium durante el bienio 1966-1967. De formación académica y con conocimientos técnicos de artes gráficas, el trabajo de Wilson se caracteriza por un personal dominio de las composiciones tipográficas, lo que Walter Medeiros

7 OWEN, Ted \& DICKSON, Denise, High Art: a history of the psychedelic poster, London, Sanctuary, 1999, p. 61.

8 SCULATTI, Gene \& SEAY, Davin, (1985), op cit., p.106.

9 Vid. ALBERS, Josef, La interacción del color, Madrid, Alianza Forma, 1979.

10 MELLOR, David, The sixties art scene in London, London, Phaidon Press, 1973, p. 170. 


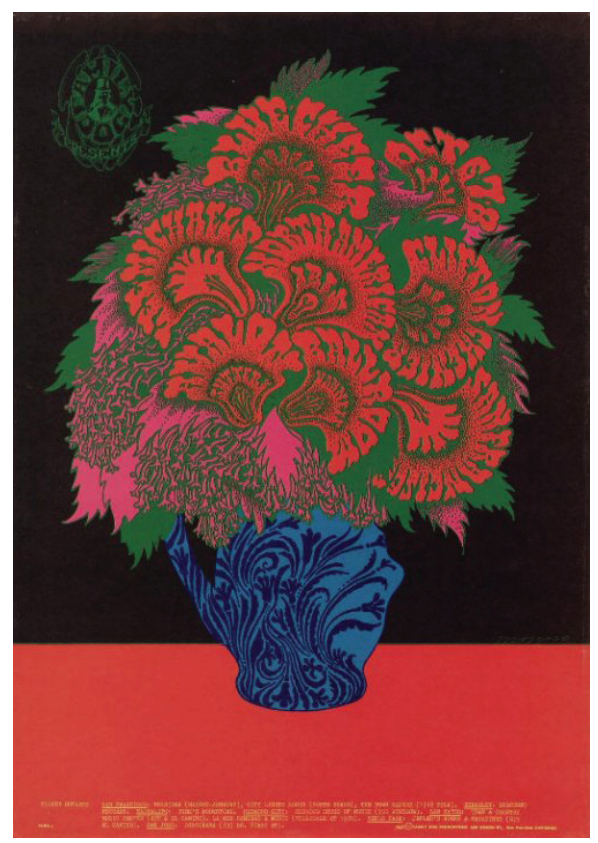

Fig.2. Victor Moscoso; Neon Rose \#12 Chambers Brothers (1967).

define como freehand lettering ${ }^{11}$, una suerte de tipografías dibujadas a mano alzada que se asientan sobre áreas delimitadas de la composición. Entre sus influencias más significativas cabe citar a los cartelistas norteamericanos William H. Bradley (18681962) y Claude Fayette Bragdon (1866-1942). En cuanto al tratamiento tipográfico es obligatorio nombrar al secesionista vienés Alfred Roller, quien ya concebía los tipos de letra como elementos compositivos desde el cartel para la XIV Exposición de la Secesión de Viena (1902) ${ }^{12}$. Un ejemplo de esta utilización expresiva de los elementos tipográficos lo podemos encontrar en Captain Beefheart. Fillmore Auditórium (1966) y en un registro mucho más psicodélico, por la dislocación tipográfica y la vibración óptica, en Moby Grape. Winterland and Fillmore Auditórium (1967).

Rick Griffin (1944-1991) evolucionó, desde unos comienzos de vinculación exclusiva a la subcultura del Surf, hasta formar parte de la élite del movimiento Hippie incluyéndose en el grupo de "Los Cinco Grandes" -The Big Five- ${ }^{13}$. Formado en el Chuinard Art Institute de Los Angeles, tuvo contactos con el escritor Ken Kesey que

11 MEDEIROS, Walter, "Poster Artists", en High Art: A history of the psychedelic poster, p. 52.

12 BARNICOAT, John, (2003), op cit., p. 31.

13 El 17 de Julio de 1967 tuvo lugar la primera exposición colectiva del grupo en la Galería Moore, de San Francisco. Se puede consultar la crítica de Thomas Albright titulada "Spirit of Mother Love MAD and the Circus", del 18 de Julio de 1967, en el San Francisco Chronicle. También es reseñable el reportaje de siete páginas sobre los pósters psicodélicos que se publicó en la revista LIFE el 1 de Septiembre de 1967 con el título "The Big Poster Hang-Up", y en el que se hacía referencia al grupo "The Big Five". 
le condujeron a San Francisco y a la LSD a través de los happenings bautizados como "Acid Tests". Sus primeros trabajos en el área de la Bahía estuvieron relacionados con el grupo de rock, The Charlatans. En ellos todavía no se vislumbra esa exuberancia caleidoscópica que será su característico marchamo. En estos primeros carteles se puede apreciar una combinación de estilos revivalistas, con la recuperación de tipografías de los "reward sheets" (carteles de busca y captura) o composiciones que beben de la iconografía circense de finales del siglo XIX y principios del XX. Un ejemplo de este tipo de carteles sería "Pow Wow".Human Be-in Golden Gate Park S.F. (1967).

Tras la inmersión psicodélica durante el periodo 1966-1968 la obra de Griffin adquiere una personalidad más acusada donde la tipografía se reviste de características biomórficas. Sus mayúsculas vibran y se asientan en un territorio lisérgico de alta ilegibilidad pero de gran efectividad en la distancia. Como afirma Harvey se trata de privilegiar la visibilidad sobre la verbalidad en un guiño a la comprensión "gestáltica" de la obra de $\operatorname{arte}^{14}$. Asimismo cabe destacar un mayor relieve en sus composiciones, tanto en los propios tipos que se proyectan hacia el espectador mediante bloques tridimensionales como en los elementos realistas (calaveras, ojos, alas, insectos, reptiles, etc.) que aparecen dotados de una profundidad distintiva. Quicksilver Kaleidoscope (1968) es un claro ejemplo de ambas premisas.

Si en Estados Unidos el fenómeno artístico contracultural de la ilustración gráfica había estado asociado con las sinergias del Rock Acido de California, en Inglaterra la psicodelia iba a tener unos referentes parcialmente distintos. Se puede hablar de una más que evidente conexión entre rock y arte auspiciada por un grupo de creadores con formación académica y muy interesados en la cultura popular norteamericana y su difusión a través de los medios de comunicación de masas. El propio Peter Blake expresa su mitomanía con nítidos homenajes a sus ídolos del rock \& roll en obras como Self-portrait with badges (1961), Bo Diddley (1963) o The Beach Boys (1964), hasta llegar a la portada del LP de The Beatles, Sgt. Pepper's Lonely Hearts Club Band (1967). Esta conexión entre Pop art y rock se patentiza también a través de anuncios en prensa, envoltorios comerciales y hasta en los decorados para programas musicales de televisión como Ready, Steady, Go! ${ }^{15}$ que se nutre de elementos iconográficos de autores como Peter Blake, Derek Boshier o Bridget Riley para decorar los escenarios con signos pop: dianas, círculos concéntricos, banderas y galones o tramas lineales y patrones geométricos con reminiscencias $O p$ art.

Hapshash and The Coloured Coat, colectivo formado por Michael English (1941) y Nigel Waymouth (1941) realizaron durante el bienio 1967-1968 el grueso de los pósters mas representativos de la psicodelia británica. Uno de sus primeros encargos fue la cobertura gráfica de todas las actuaciones en la discoteca UFO (Unlimited Freak Out), ubicada en el corazón de Londres, concretamente en Tottenham Court $\operatorname{Road}^{16}$.

14 HARVEY, Doug, "Rick Griffin: Just another mad artist or draftsman of the sacred", en Heart and Torch: Rick Griffin's Transcendence, Laguna Beach, California, Laguna Art Museum \& Gingko Press, 2007, p. 33.

15 Emitido en Inglaterra a través de la cadena privada Redifusión, desde Agosto de 1963.

16 GREEN, Jonathan, All Dressed Up. The Sixties and the Counterculture, London, Pimlico, 1999, p. 217. 
En líneas generales los diseños de Hapshash and The coloured Coat compartían muchos de los elementos compositivos, cromáticos y tipográficos de sus homólogos californianos aunque con algunas señas distintivas. El propio English lo deja entrever en su autobiografía $3 D$ Eye: "Estaba fascinado con las formas sinuosas de los trabajos de Mucha, Beardsley y Rackham. Todos nuestros pósters de esa época contenían algunos signos secretos, formas prehistóricas y platillos volantes. Mezclábamos la sexualidad con la mitología fantástica. Dragones y vello púbico" ${ }^{17}$. Un ejemplo de su trabajo lo encontramos en Pink Floyd. UFO Club (1967), donde paisajes siderales y hadas desnudas comparten espacio con pájaros biomecánicos y naves espaciales.

Entre los nombres propios de la ilustración psicodélica inglesa cabe destacar la obra de Martin Sharp (1941), de origen australiano -Sydney- y emigrado a Londres en 1966. Las portadas de los discos del grupo Cream, Disraeli Gears (1967) y Wheels of Fire (1968) se encuentran entre las obras más definitorias de su estilo. Asimismo son destacables sus pósters de temas genéricos realizados para su venta y distribución a través de la compañía Big O Poster. Entre ellos se debe reseñar Vincent (1967), un homenaje a Van Gogh en el que las influencias del "comix underground USA" son más que evidentes al presentar la composición en espacios delimitados, a modo de viñetas. El tratamiento gráfico remite a las explosiones, ondulaciones y distorsiones visuales producidas durante la experiencia psicodélica en la que el espacio -constreñido- y el color -vibrante- favorecen los efectos alucinatorios. Por lo que respecta a los pósters anunciadores de conciertos la obra de Sharp sigue las directrices de la psicodelia al uso, con tipografías globulares de asequible legibilidad y elementos gráficos (guitarras, corazones, ojos, labios y estrellas) todos ellos imbuidos de una volumetría pulsante y líquida. Se pueden comprobar estos caracteres en una obra como UFO at the Roundhouse (1967).

\section{PORTADAS DE LP}

Con la explosiva irrupción de The Beatles en los primeros años de la década de los sesenta el carácter de la música popular británica ejecuta un cambio drástico: pasa de ser mera imitación de los ídolos norteamericanos para erigirse en epicentro de una nueva ola audiovisual. Donde antes aparecía un solista ahora se presenta un conjunto con varios miembros. Si antes el diseño de las portadas no pasaba por ser más que la cotidiana y estandarizada labor del departamento correspondiente de una compañía de discos, ahora comienza a contemplarse la posibilidad de una evolución hacia composiciones más creativas en las que fotografia, ilustración, textos y tipografía logren trasladar el nuevo ímpetu del rock.

The Beatles, como vanguardia y reflejo de gran parte del movimiento cultural y subcultural que se estaba produciendo en ese periodo nos puede servir como clave para introducir esas novedades iconográficas. Ya en su segundo LP, With The Beatles (1964) se pueden apreciar algunos cambios. De la sencilla fotografía de grupo y la

17 ENGLISH, Michael, 3D Eye, Surrey, Paper Tiger, 1979, p. 56. 
sucinta información textual se había pasado a un concepto más elaborado. El retrato frontal en un contrastado blanco y negro mostraba a los cuatro integrantes en una actitud diferente, alejada de la jovialidad imperante. Robert Freeman (1941), un joven fotógrafo desconocido entonces adquirirá fama internacional a partir de este momento y realizará consecutivamente las cuatro fotografias de portada de los siguientes LP del grupo: A Hard Day's Night (1964), Beatles For Sale (1964), Help (1965) y Rubber Soul (1965).

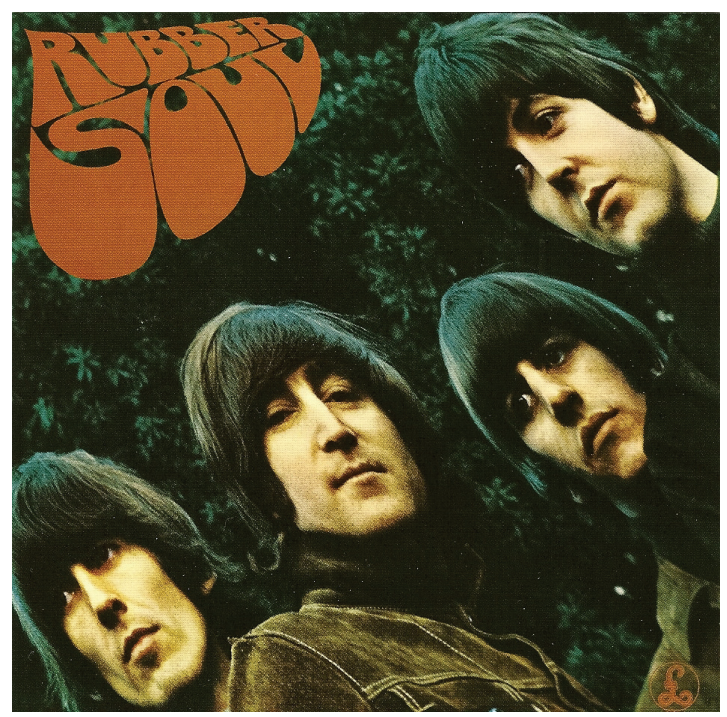

Fig.3. The Beatles; Rubber Soul (1965).

La portada de Rubber Soul (1965) (fig. 3) es la que sirve para anticipar los primeros rasgos psicodélicos. Ya la música introduce una serie de novedades: los arreglos enriquecen las composiciones pop, las texturas sonoras se amplían con la inclusión de instrumentos hasta ahora ajenos al género como cuartetos de cuerda, armónium, mellotron o sitar. Los textos comienzan un viaje sin retorno hacia la introspección y el lirismo, cuando no lanzan mensajes encriptados con referencia a la irrupción de las drogas. Nuevamente es Robert Freeman quien se encarga de retratar al grupo, en esta ocasión en color y en un entorno boscoso. La gama cromática de tonalidades pardas sólo se ve alterada por la tipografía globular en rojo con el título del álbum -Rubber Soul-. El encuadre efectúa un sutil contrapicado creando un juego de diagonales entre el citado título del disco y los componentes del grupo. Como rasgo pre-psicodélico se observa la distorsión de los rostros creada por el propio Freeman en el laboratorio.

A raíz de la senda abierta por The Beatles otros artistas muestran un interés similar en el progreso hacia esos terrenos de experimentación y evolución audiovisual. Bob Dylan ofrece portadas que reflejan esa sintonía en LPs como Bringing It All Back Home (1965) o Blonde On Blonde (1966), donde las fotografías de Daniel Kramer 
y Jerry Schatzberg respectivamente, a medio camino entre la distorsión y el desenfoque, conectan de una manera fehaciente una música que se nutre de los ritmos y melodías pop pero que proyecta una serie de proclamas indescifrables más cercanas a la poesía visionaria, una dislocada mixtura de folk, rock y alucinaciones.

La utilización de trucos fotográficos, tanto a la hora del revelado y positivado en el laboratorio (solarizado, tramas, negativo forzado, película infrarroja, etc.) como a través del empleo de lentes (teleobjetivo, gran angular, ojo de pez) o filtros para lograr efectos multiplicadores o veladuras (poliedros, medias, vaselina) proliferaron como recurso psicodélico de primer orden. Así se pueden citar las portadas del primer LP de Pink Floyd, The Piper At the Gates Of Dawn (1967), obra del fotógrafo de origen hindú Vic Singh, con el efecto caleidoscópico creado por un filtro multiprisma, o la de The Aynsley Dunbar Retaliation, Doctor's Dunbar Prescription (1968) con la presentación del grupo a través de un negativo directo de película infrarroja. En este caso la obra corresponde al colectivo Hipgnosis, formado en Londres por el diseñador Storm Thorgerson y el fotógrafo Aubrey Powell ${ }^{18}$.

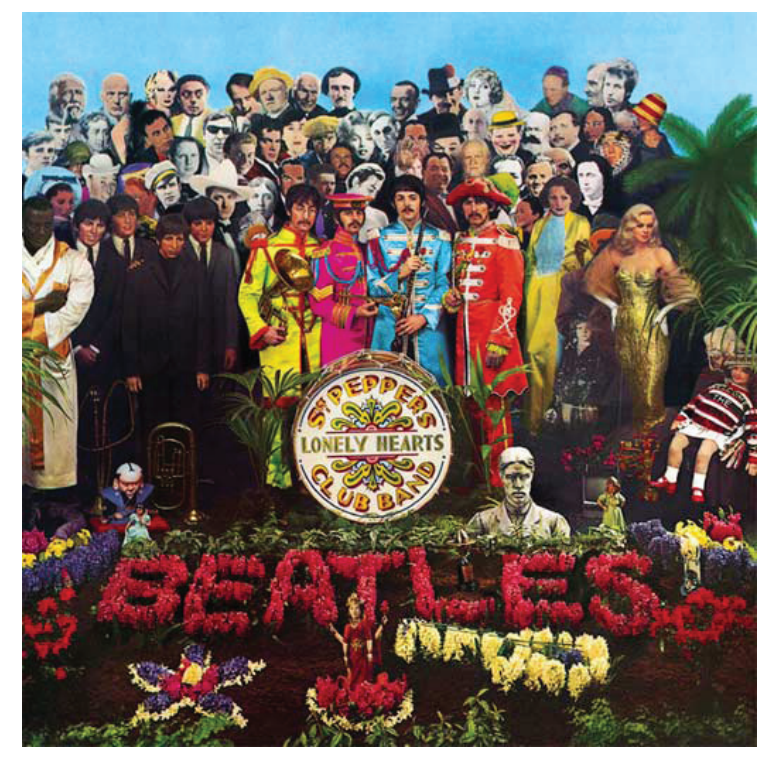

Fig.4. The Beatles; Sgt. Peppers Lonely Hearts Club Band (1967).

Nuevamente es obligado volver a The Beatles para encontrar uno de los referentes paradigmáticos de la psicodelia, su LP, Sgt. Pepper's Lonely Hearts Club Band (1967) (fig. 4). Ahora el grupo pretende, desde la funda doble, suplantarse a si mismo, huir

18 Sobre la obra de Hipgnosis se pueden consultar los textos de: THORGERSON, Storm, Walk Away René: The work of Hipgnosis, London, Paper Tiger, 1978. También: POWELL, Aubrey, For The Love of Vinyl, London, Picture Box, 2008. 
de su propio éxito, hastiados (en sólo tres años) de la histeria colectiva denominada Beatlemania y de las extenuantes giras mundiales, dedicando todos sus esfuerzos a la composición musical y a la investigación de las posibilidades técnicas del estudio de grabación logrando facturar una de las cimas del pop y el rock de los años sesenta. El concepto de la portada corresponde a Peter Blake (1932) en colaboración con su esposa Jann Haworth que habían sido introducidos en el círculo Beatle por medio del galerista Robert Fraser ${ }^{19}$. En un collage a tamaño natural fotografiado por Michael Cooper se presenta un heterogéneo grupo de figuras recortadas y ensambladas sobre siluetas de cartón. Son exactamente 73 personajes junto a otros 14 artefactos diversos que se entremezclan en un desvarío inaudito y sin precedentes para una carátula discográfica $^{20}$. Los propios Beatles de la época de la Beatlemania, cedidos por el museo de cera de Madame Tussaud, asisten impertérritos a la presentación colorista de sus réplicas auténticas, de carne y hueso. Un abigarrado grupo de figuras se solapan al fondo dando lugar a un auditorio imposible: Marlon Brando junto a Oscar Wilde, Fred Astaire al lado de Carl Gustav Jung o Karlheinz Stockhausen entre Mae West y Aubrey Beardsley. Los Beatles reales se reinventan a si mismos como miembros de la Banda de Corazones Solitarios del Sargento Pimienta y confirman su nueva identidad ficticia desde el fotomontaje de la portada luciendo estridentes uniformes de satén. El título del disco queda enmarcado en un elemento real de la parafernalia de artefactos -el parche delantero de un bombo de orquesta-, que ya no es un añadido tipográfico externo, ahora forma parte de la realidad visual de la puesta en escena y su caligrafía remite a fuentes victorianas o eduardianas como un guiño camp a la recuperación de un pasado glorioso: el del caduco imperio británico de finales del siglo XIX y principios del XX.

La portada refleja el halo caleidoscópico y la extravagancia lírico-psicodélica que emana de las trece canciones del LP: apuntes orientales, efectos de sonido, recursos electrónicos, reminiscencias barrocas, folklóricas y hasta vodevil. Sgt. Pepper's barre las convenciones de la música pop del momento y tras su estela se instala la libertad más absoluta a la hora de relacionar las canciones de un grupo o solista con las imágenes que se ofrecen en la portada. En palabras de Evans: "las portadas de los discos de The Beatles, tanto en la mente del propio grupo como en la opinión de críticos y fans, han asumido ya el estatus de obras de arte"21.

Sin salir de Inglaterra son destacables los trabajos de Klaus Voorman. Su portada para The Beatles, Revolver (1966), puede ser considerada como un precedente de Sgt. Peppers y las posibilidades expresivas del formato LP. En su concepción como collage de fotos suministradas por los integrantes del grupo y la aportación del trazo lineal de los retratos de Voorman se aprecia ya una evolución ante la escueta fotografía promocional de las carátulas precedentes. Hay un claro referente a la obra de Aubrey Beardsley, de plena actualidad tras la retrospectiva ofrecida por el Victoria \& Albert Museum en ese mismo verano de $1966^{22}$.

19 GREEN, Jonathan, (1999), op cit., p. 91.

20 Se puede consultar la relación completa de personajes y objetos en la página: www.iamthebeatles.com

21 EVANS, Mike, The Art of The Beatles, New York, Beach Tree Books, 1984, p. 96.

22 GUFFEY, Elizabeth E., Retro: The culture of revival, London, Reaktion Books, 2006, p. 53. 
Ya absolutamente integradas en la iconografía psicodélica cabría citar las portadas para The Incredible String Band, The 5000 Spirits or The Layers of The Onion (1967), obra del colectivo holandés afincado en Inglaterra, The Fool, donde las calidades del renovado folk británico, trufado de acentos psicodélicos en los textos (bosques, hadas, gnomos, conjuros y pócimas) y en las melodías (ululantes texturas armónicas e instrumentación acústica) afloran a la superficie de la carátula en forma de estallido cromático más cercano a la ingenuidad de Henri Rousseau que a los logros esquemáticos de Voorman o el concepto pop de Blake.

También se puede citar la portada del LP del trío Cream, Disraeli Gears (1967) en la que a partir de una fotografía de Robert Whitaker, Martin Sharp (ya reseñado como diseñador de pósters) estructura un explosivo collage en el que los tonos fluorescentes procuran la vibración psicodélica. Interesante resulta en este caso la contraportada pues resulta una continuación, un complemento discursivo de lo que ofrece la portada. Tras el fogonazo cromático, la información textual escueta: los títulos de las canciones y un collage arbitrario de fotografías de los miembros del grupo, amigos, novias y colaboradores entre flores pintadas, globos oculares y otros objetos en una disposición abigarrada, en un delirante horror vacui.

Si el trabajo de los diseñadores de la psicodelia inglesa bebe de fuentes diversas de regusto europeo (collage, experimentación fotográfica o motivos florales), para tratar de representar esos estados visionarios y establecer un nexo sinestésico entre música e imágenes, sus homólogos norteamericanos siguen los principios ya mencionados para la realización de los pósters anunciadores de conciertos: predilección por elementos tomados del Art Nouveau (sinuosidad botánica) y aromas surrealistas (objetos descontextualizados). De este modo se repiten las líneas orgánicas, tanto para la ilustración como para la creación de emblemas y logotipos, aunque con un marcado énfasis en la confusión, en la transformación de los caracteres textuales en elementos dotados de volumetría palpitante. Simplemente una letra puede establecer ese nexo psicodélico, esa llave que abra las "puertas de la percepción". Muchas de estas constantes están presentes en portadas como Aoxomoxoa (1969) (fig. 5), del grupo californiano Grateful Dead, obra del ya citado Rick Griffin. Aquí, en una composición canónica (nombre del grupo centrado en la parte superior y título del disco sobre el plano horizontal inferior), la morfología tipográfica proporciona la conexión psicodélica. Las letras vibran y se proyectan hacia el espectador con afilados vértices. Un microcosmos de objetos perfilados en esferas volumétricas que se activarán al compás de la música y del ácido lisérgico flotan suspendidos: calaveras, formas arbóreas, hongos, ovoides, raíces, pebeteros, reptiles, insectos, etc.

Víctor Moscoso, miembro asimismo del destacado grupo de creadores de pósters, realizó portadas en las que se preocupó por dotar a las imágenes de una alta vibración cromática como carácter distintivo también presente en sus trabajos cartelísticos. Como ejemplo podemos citar la portada para Steve Miller Band, Children Of The Future (1968) donde la combinación de tonos saturados y contiguos crea una 


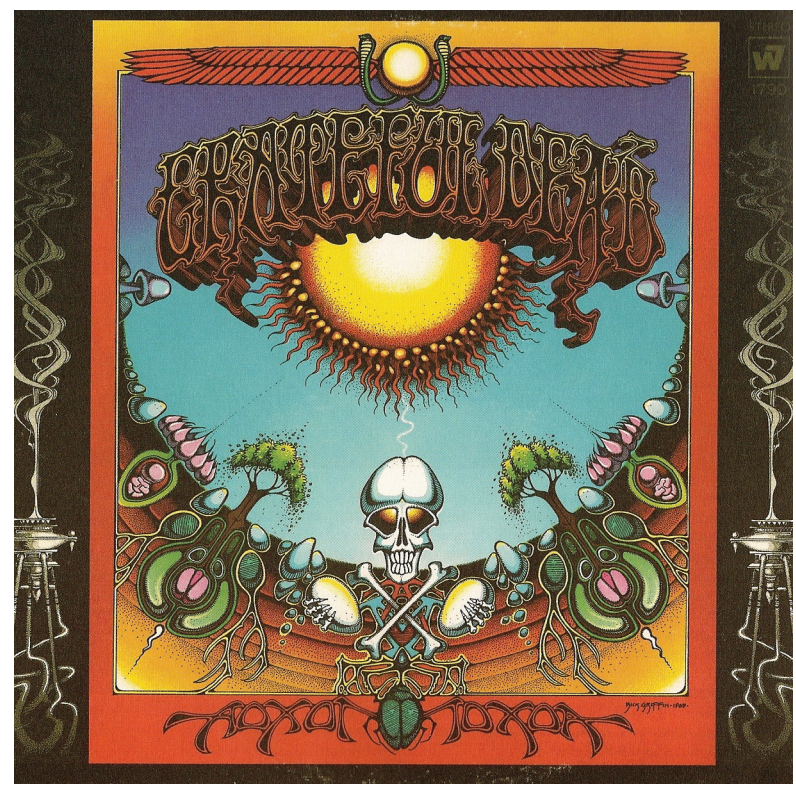

Fig.5. Grateful Dead; Aoxomoxoa (1969).

vibración óptica cercana a los trabajos coetáneos de artistas como Victor Vasarely o Bridget Riley ${ }^{23}$.

En un registro muy diferente podríamos citar el trabajo de Bob Cato para el quinteto de San Francisco, Moby Grape, Wow (1968), donde rompe claramente con la morfología de caracteres psicodélicos al uso; no hay colores vibrantes, ni tipografías crípticas, ni arabescos globulares; por el contrario Cato, de ascendencia mexicana y formación académica (había tenido como maestros a los muralistas José Clemente Orozco y David Alfaro Siqueiros), factura una imagen que bebe del surrealismo: una mixtura figurativa de elementos descontextualizados y en una escala irreal que recuerda los collages de Max Ernst o muchos de los paisajes desoladores que aparecen de fondo en diversas obras de Salvador Dalí.

Es también interesante reseñar la conexión entre los tebeos para quinceañeros y su evolución hacia el denominado Comix Underground y como éste y su lenguaje viñeteado pasan a formar parte de la iconografía psicodélica. Como ejemplo podemos citar la portada que el dibujante Robert Crumb realizó para el grupo Big Brother \& The Holding Company, Cheap Thrills (1968) en la que su personal iconografía (mujeres voluptuosas, ciudadanos vulgares, predicadores iluminados o hippies fumados) servía para ilustrar, viñeta a viñeta, las canciones del disco y sus correspondientes créditos, todo ello en una traslación directa de la retórica del Comix Underground,

23 DE VILLE, Nick, Album; Classic Sleeve Design, London, Mitchell Beazley, 2003, p. 96. 
pleno de referencias al sexo, las drogas y el hedonismo contracultural en una portada altamente psicodélica que creó escuela.

Como colofón a este repaso por los creadores de portadas psicodélicas resulta muy pertinente reseñar la obra de Mati Klarwein (1932-2002), representante de una tendencia más pictórica, cercana a un surrealismo tribal y menos deudora de las tipologías derivadas del Art Nouveau. Sus trabajos, tanto para el grupo chicano de rock, Santana, como para el trompetista Miles Davis resultan prototípicos de las posibilidades plásticas del formato LP. Para Santana, Klarwein realizó la portada de su segundo álbum, Abraxas (1970) a partir de una obra precedente: Annunciation, que formaba parte, a su vez, de la decoración del Aleph Sanctuary, pequeña capilla profana ubicada en la Isla de Mallorca y en la que Klarwein había venido trabajando desde 1963. En la carátula para Santana la iconografía cristiana se subvierte; el ángel Gabriel es ahora una figura femenina alada que sostiene entre sus muslos una conga mientras la virgen María ha mutado en diosa africana, desnuda y rotunda. El fondo de la representación es un frenesí multicolor ornado con detalles botánicos, geológicos, cosméticos y decorativos tratados con minuciosidad microscópica y que se proyectan en un continuo hacia la contraportada. La tipografía, diseñada por Robert Venosa es otro de los logros de esta portada, genuino paradigma de la conjunción música/ imagen, donde ambas se presentan calientes, sensuales y desinhibidas. Un exótico epitafio psicodélico para la década que ya tocaba a su fin.

Para finalizar este sintético recorrido por las diferentes interpretaciones plásticas de lo psicodélico cabría concluir en primer lugar que es en estos dos medios ya desmenuzados -carteles anunciadores y portadas de discos- donde la expresión, o porqué no, el arte psicodélico, adquiere una mayor difusión, relevancia y razón de ser conjugando fehacientemente las propuestas coetáneas de agitación contracultural y frivolidad pop. Por lo que respecta a las variables tipológicas sería recomendable un más amplio y proteico estudio para mostrar con mayor profundidad y detalle aspectos distintivos, fuentes específicas y logros propios de cada ramificación estilística, aunque la selección de obras y artistas aquí expuesto sirve a nuestros fines de presentar las diversas manifestaciones plásticas de un fenómeno que se diluye entre lo cultural, lo comercial y lo artístico: la psicodelia. 